\title{
Achievement Motivation and Parenting Styles in Promoting Effective Learning Among Secondary School Students in Ondo State
}

\author{
Ojewola, Florence O., PhD \\ Faremi, Yinusa A., PhD \\ Department of Guidance and Counselling, Adekunle Ajasin University, \\ Akungba-Akoko, Ondo State, Nigeria
}

Doi: 10.19044/esj.2018.v14n4p392 URL:http://dx.doi.org/10.19044/esj.2018.v14n4p392

\begin{abstract}
Effective learning among secondary school students in Ondo state has become a source of concern to all well-meaning people in the educational sector hence this study investigated achievement motivation and parenting styles in promoting effective learning among secondary school students in Ondo State. Descriptive survey design was adopted for this study. The sample was made up of 245 secondary school students randomly selected from five local government areas in Ondo state. A questionnaire titled Assessment of Secondary School Students Academic Achievement Motivation for Promoting Learning. Questionnaire was administered on the students to assess their achievement motivation and parenting styles in enhancing effective learning among secondary school students. Data collected were analysed using Analysis of Variance and t-test. The three null hypotheses formulated were tested at 0.05 alpha level. The results revealed that there was no significant difference between academic achievement motivation and parenting styles of secondary school students. The other two hypotheses based on family structure and gender were not rejected. It was concluded that achievement motivation and the styles adopted by parents in raising their children may not have any impact on the secondary school students' effective learning outcome. It was also recommended among others that teachers and parents should make their students to develop achievement motivation.
\end{abstract}

Keywords: Achievement, Motivation, Parenting styles, Effective learning, Secondary school

\section{Background to the study}

Achievement motivation is regarded as what causes a person to make effort to become successful and be goal oriented. The desire to achieve and 
become great in life is no longer the ambition of many secondary school students in Nigeria. Thus laziness and mediocrity is highly promoted and exhibited by many secondary school students who are supposed to be greatly motivated for efficient learning in schools. Denhardt, Denhartdt and Aristigueta (2008) viewed motivation as what causes people to behave as they do. Soltanzadeh, Hashemi and Shahi (2013) asserted that motivation is seen as one of the most important psychological concept in education. They noted that this can be classified into two which are - intrinsic and extrinsic motivation. Intrinsic motivation refers to doing something because it is inherently interesting or enjoyable while extrinsic motivation involves engaging in a behaviour to earn external rewards or avoid punishment. Intrinsic academic motivation or academic achievement motivation could result in better educational outcomes such as higher academic performances, better quality of learning, increased persistence, effort studies and better psychological adjustment of learners in comparison to extrinsic motivation (Soltanzadeh, Hashemi\&Shahi, 2013).

Wakpainjan and Jadham (2012) see achievement motivation as the student's ability to take risk, formulate goal and achieve them. Whereas, Mullins (2010) observed that the underlying concept of motivation is the driving force within individual which they attempt to achieve some goals in order to fulfil some need or expectation. It is noted that motivation of students' in education and the impact on academic performance are considered as an important aspect of effective learning. The reaction of a learner to education to some extent is determine by the level he/she will go in education. It is evident that students who possess high intrinsic and extrinsic motivation tend to attain higher cognitive achievement than those with low intrinsic and extrinsic motivation in their course of study (Onuk \&Durowoju, 2011).

The major theories of achievement motivation were propounded by McClelland, Atkinson and Heckhausen (Wigfield\&Eccles, 2002) achievement motivation is seen as the resulting tendency of an emotional conflict between the motive of achieving success and the motive of avoiding failure. The core of both motivational tendencies is formed by two achievement needs which include the need for success and the need to avoid failure which are independent of each other. Polednova, Stranska and Niedobova (2014) expressed achievement motivation as the drive to achieve which is present to some degree in all individual. The motivation of student is an important aspect of effective learning and instruction. When students are motivated to perform competently on academic tasks they will learn in accordance with their abilities. Learning by students can be maximised when their achievement motivation is enhanced (Kambi \&Varsha, 2014).

Studies have revealed that on the average girls do better in school than boys. Girls tend to get higher grades and complete high school at a higher rate 
compared to boys (NCE, 2003). Standardized achievement tests also show that females are better on test of literacy, writing and general knowledge (National Center for Education Statistics, 2003). According to the finding of Kumari and Chamund (2015) girls in all the three systems of education were found to be significantly better in achievement motivation, study habits and academic achievement when compared with boys in the same school. Abijo (2008) equally found that females had greater achievement in essay writing than their male counterpart.

Parenting styles is another important variable that can affect adolescents' achievement for effective learning. Parenting style can make a student to achieve academically or not to attain any success in life. It was found that the more autonomy, demand and support parents provided, the more the students were confident and persistent academically. Three parenting styles have been identified these include authoritative, permissive and authoritarian. Authoritative parenting is characterised by high levels of nurturance, involvement, sensitivity, reasoning and encouragement of autonomy. Parents who direct the activities and decisions for their children through reasoning and discipline would be described as authoritative. Permissive parenting is characterised by making few demands, exhibiting noncontrolling behaviour and using minimal punishment. Parents who do not establish rules and guidelines for their children's behaviour would be described as possessing a permissive parenting style. Authoritarian parenting tends to fall at the other end of the continuum. Parents characterised as authoritarian exhibit highly directive behaviour, high level of restriction and rejection behaviour and power asserting behaviours. These parents tend to have a philosophy that it's my way or the highway (Reitman, Rhode, Hupp\&Altebello, 2002).

Researchers have found a positive relationship between authoritative parenting and academic performance (Ingoldby, Schvanevelde, Supple \& Bush, 2003). It has been found that the more autonomy, demand and support parents provided, the more students were confident and persistent academically. Authoritative parenting was found to continue having an influence on students' academic performance (Evlanger, Megan \& Robert, 2009). Researchers have found that parenting styles and college students' grade point average (GPA) are not related (Joshi, Ferris, Otto \& Regan, 2003). Parenting style has been examined in many adolescent academic achievement (Wintre \&Yaffe, 2000; Star, 2011).

Achievement motivation has been found to be related to family type that is the issue of monogamy and polygamy are found to affect a child's academic performance. This assertion is supported by Adesehinwa (2013) who found that variance in psycho-social emotional fortification in the monogamy and polygamy family background could be an indicator to high or 
low academic performance. She further noted that students from polygamous families are therefore more likely to experience more problems than students from monogamous families. This will invariably affect their academic achievement. This is because psychological problems are potential sources of trouble with learning (Adesehinwa, 2013). UNICEF (2011) conducted a study in America and found that the influence of type of family structure on academic success continue through high school. Nato (2016) opined that the types of family structure substantially influence outcomes such as high school dropout rates, graduation rates and age at first pregnancy. Adesehinwa (2013) found that there is a significant difference in the overall academic achievement of students from monogamous families and those from polygamous families.

\section{Statement of Problem}

It is evident that today secondary school students lack achievement motivation. There are many who are in the school who do not have serious ambition to succeed. Many of these students lack adequate motivation needed to be successful in their life endeavours. There are many of these students who do not know why they are in the school, they do not have the desire to succeed or excel. This is not to say that there are quite a lot of students who are ambitious and desire to succeed. Some of these students are working hard to succeed and make it in life.

The rate of adverse behaviour among secondary school students is alarming that one may be tempted to ask whether these students really know why they are in school. The contemporary problems in Nigeria notwithstanding the future of these adolescents should be of paramount importance to all and sundry. These youths are the future of the nation thus they must not be neglected, against this background, these researchers attempt to address the of influence of achievement motivation and parenting styles in promoting effective learning among secondary school students in Ondo State.

Parenting styles also have serious issue in enhancing achievement motivation among adolescents. There are parents with different attitudes to the academic achievement of their children. Some parents are supportive of their children academic growth and development, while some are not bothered whether their children succeed or not. For students to make progress and be motivated for achievement, parental support is very essential. This is in line with the assertion of Seginer 2006, who noted that parental involvement is a complex construct associated with students' success. The involvement of parents' in academic achievement motivation of students is very essential, the level of the students' academic pursuit notwithstanding. Some researchers have argued that parental involvement may be beneficial not only to the elementary age students but also adolescents (Hill \& Tyson, 2009).

On the basis of these issues, the following hypotheses were generated: 
1. There is no significant difference between academic achievement motivation and parenting styles in promoting effective learning among secondary school students.

2. There is no significant difference between academic achievement motivation in promoting effective learning between students from polygamous and monogamous family structures.

3. There is no significant difference between academic achievement motivation in promoting effective learning between male and female students.

\section{Methodology}

This is a descriptive research that involved survey type. It adopted questionnaire to capture large proportion of the population to obtain and describe the opinion of the respondents, describing the achievement motivation and parenting styles in promoting effective learning among secondary school students.

The population of the study consisted of all secondary school students in North East Local Government area of Ondo State. Simple random sampling technique was used to select Two hundred and forty-five(245) students from eight different schools in North East Local Government area of Ondo State. Assessment of Secondary School Students`Academic Achievement Motivation and Parenting Styles for Promoting Learning Questionnaire was the instrument used to collect data for the study. It consisted of Section A and B

Section A:Consisted of information on respondents demographic data such as age, gender and parenting styles while Section B consisted of information on Achievement Motivation and Parenting Styles. Expert Opinions were consulted to ascertain the face and content validity of the instrument used. Test-retest method was used to find the reliability of the instrument. The data collected were analysed using Pearson Product Moment Correlation and the reliability was found to be 0.75

The researchers personally visited the sampled public secondary schools within Ondo North Senatorial District to administer the questionnaire by hand. The respondents were carefully given explanation on the purpose and intention of the research work. The questionnaire was distributed to the respondents by hand and retrieved immediately after completion for the purpose of data analysis.

\section{Results}

Ho1There is no significant difference between academic achievement motivation and parenting styles in promoting effective learning among secondary school students. 
In treating this hypothesis academic achievement motivation results were computed with parenting styles scores of respondents using ANOVA.

Table 1: ANOVA summary of Students' Academic Achievement Motivation and

Parenting Styles

\begin{tabular}{llllll}
\hline Source & SS & Df & MS & $F_{\text {cal }}$ & $F_{\text {table }}$ \\
\hline Between groups & 238.15 & 2 & 119.076 & & \\
Within groups & 18770.889 & 242 & 77.56 & 1.535 & 3.04 \\
Total & 19009.020 & 244 & & & \\
\hline
\end{tabular}

The result indicated that there is no significant difference between the academic achievement motivation and parenting styles of the secondary school students in promoting effective learning (f2, $242=1.535, \mathrm{P}>0.05$ ). This hypothesis of no significant difference was not rejected. This implied that there is no significant difference between academic achievement motivation and parenting styles in promoting effective learning among secondary school students.

$\mathrm{Ho}_{2}$ There is no significant difference between academic achievement motivation in promoting effective learning among students from polygamous and monogamous family structures.

In treating this hypothesis scores from the academic achievement motivation was computed using t-test scores of students from polygamy and monogamy families.

Table 2: t-test of Family Structure and Students' Academic Achievement Motivation on effective learning

\begin{tabular}{lllllll}
\hline Family structure & $\mathbf{N}$ & Mean & SD & df & $\mathbf{t}_{\text {cal }}$ & $\mathbf{t}_{\text {table }}$ \\
\hline Polygamy & 86 & 70.65 & 10.92 & & & 1.465 \\
& & & & & 1.960 \\
Monogamy & 159 & 68.92 & 7.50 & & & \\
\hline
\end{tabular}

The result in table 2 shows that $t_{\text {cal }}(1.465)$ is less than $t_{\text {table }}(1.960)$ at 0.05 level of significance. This hypothesis of no significant difference was not rejected. This implies that there is no significant difference between academic achievement motivation on effective learning among students from polygamous and monogamous family structures.

$\mathrm{Ho}_{3}$ There is no significant difference between academic achievement motivation in promoting effective learning among male and female students.

In testing this hypothesis, scores of students' academic achievement motivation was computed using the t-test scores of students based on gender. Table 3:t-test of students' Academic Achievement Motivation for effective learning on the basis of Gender

\begin{tabular}{|c|c|c|c|c|c|c|}
\hline Gender & $\mathbf{N}$ & Mean & SD & df & $t_{\text {cal }}$ & $\mathbf{t}_{\text {table }}$ \\
\hline Male & 74 & 69.16 & 8.90 & & & \\
\hline Female & 171 & 69.69 & 8.82 & 243 & 0.429 & 1.960 \\
\hline
\end{tabular}


Table 3 reveals that there is no significant difference between students' academic achievement motivation for effective learning on the basis of gender $(\mathrm{t}(243)=0.429, \mathrm{P}>0.05)$. This hypothesis of no significant difference is not rejected. Hence there is no significant difference between academic achievement motivation and gender of secondary school students.

\section{Discussion}

The result of the first hypothesis tested showed no significant difference between academic achievement motivation and parenting styles of the secondary school students. Whereas results from the findings of Ingoldby, Schvaneuelde, Supple \& Bush, 2003 showed that positive relationship existed between authoritative parenting and academic performance. Authoritative parenting was found to continue having an influence on students' academic performance (Erlanger, Megan \& Robert, 2009). While the findings of Joshi, Ferris, Otto \& Regan (2003) stated that parenting styles and college students grade point average (GPA) are not related. This is in consonance with the findings of the first hypothesis. A student that will perform well academically will do well, the parenting styles not withstanding. The parenting styles whether authoritative, authoritarian or permissive may not necessarily have any serious effect on students' achievement motivation but the attitude of an individual could affect their motivation

The result of the second hypothesis also indicated that there is no significant difference between academic achievement motivation and family structure. The fact that a student is from a polygamous or monogamous home should not affect their achievement motivation. Family structure may not necessarily affect a student achievement motivation. A polygamous home could be well structured to the extent that adequate care, warmth and acceptance is readily available for a child than even a monogamous set up where there is constant misunderstanding, quarrels and inadequate care for a child. This is at variance with findings of Adesehinwa (2013) who found that psycho-social emotional fortification in the monogamy and polygamy family background could be an indicator to high or low academic performance. Nato (2016) also found that the types of family structure substantially influence outcomes such as high school dropout rates, graduation rates and age at first pregnancy. Adesehinwa (2013) found a significant difference in overall academic achievement of students from polygamous families and those from monogamous families.

The result of the third hypothesis also indicated no significant difference between academic achievement motivations on the basis of gender. This is contrary to the study conducted by National Center for Education Statistics, 2003, that found on the average that girls do better in school than boys. They found that girls tend to get higher grades and complete high school 
at a higher rate compared to boys. Again, they stated that standardized achievement tests show that females are better at spelling and perform better on test of literacy, writing and general knowledge. Kumara and Chamnd (2015) equally found that girls in all the three systems of education were found to be significantly better in achievement motivation, study habits and academic achievement when compared with boys in the same school. All these assertions are contrary to the findings of this research work thus both males and females can be motivated for academic achievement. Both the male and female students should desire to succeed; hence all must labour very hard to achieve their dreams and aspirations in life. Students should be up and doing and avoid indolence and laziness if they want to achieve greatness in life.

\section{Conclusion}

The result of the findings indicated that there is no significant difference between academic achievement motivation and parenting styles in promoting effective learning among secondary school students. That is to say that academic achievement motivation was not affected by parenting styles that parents adopt in raising their children. The result also showed that there is no significant difference between academic achievement motivation and effective learning among students from polygamy and monogamy family structures. The findings also revealed that there is no significant difference between academic achievement motivation and effective learning among adolescents on the basis of gender.

- Counsellors and teachers must be able to do their best to help these students to be better motivated for academic achievement. Counsellors must make use of all necessary psychological skills and theories to enhance efficiency and right attitude to academic among secondary school students.

- Parents/Guardians, teachers and the general public should be exposed to seminars which will help to promote positive attitude in students to develop academic achievement motivation.

- Teachers' should make their students develop appropriate achievement motivation. Teachers' are role model, there is need to train up these students with the right skills which will enhance their future development. Negative and uncomplimentary comments should be avoided because this could jeopardise the future of these young ones.

- Parents should endeavour to utilise good parenting styles that will enhance the academic achievement of their children or wards. 


\section{References:}

1. Abijo, J. A. (2008). Effect of two methods of teaching essay writing on students' learning outcomes in Yoruba language at the senior secondary school level $\mathrm{PhD}$ Thesis. Institute of Education University of Ibadan.

2. Adesehinwa, O. A. (2013). Effects of family type: Monogamy or polygamy on students academic achievement in Nigeria. Int. J. of Psychology and Counselling 5 (7), 153-156

DOI 10.5897/ IJPC 10.02 ISBN 2141-2499

3. Denhardt, R. B.;Denhardt, J. V. \&Aristigueta, M. P. (2008): Managing human behaviour in public and non-profit organization. Journal of Personality and Social Psychology 47, $944-952$.

4. Erlanger, A. T.; Megan, C. \& Robert, W. H. (2009). The influence of parenting styles, achievement motivation and self-efficacy on academic performance in college students. Journal of College Student Development 50(3), 337 - 346.

5. Hill, N. E. \& Tyson, D. F. (2009). Parental involvement in middle school: A meta-analytic assessment of the strategies that promote achievement development psychology, 45, 740 - 763. htpp://dx.doi.org/10.1037/a0015362.

6. Ingoldby, B.;Schvanevelde, B.; Supple, A.\& Bush, K. (2003).The relationship between parenting and adolescent achievement and selfefficacy in Chile and

7. Ecuador.Marriageand Family Review 35(3), 139-159.

8. Joshi, A.; Ferris, J.; Otto, A. \& Regan, P. (2003).Parenting styles and academic achievement in college students.Psychological Reports, 93, $823-832$.

9. Kambiz, Y. \&Varsha, S. G. (2014).Studying the role of habits and achievement motivation in improving students' academic performance.European online Journal of Natural and Social Sciences 3(4), 827 - 839.

10. Kumari, U. R. S. \&Chamundeswari, S. (2015). Achievement motivation, study habits and academic achievement of students at the secondary level. International Journal of Emerging Research in Management and Technology 4, (10), 7 - 13.

11. Mullins, L. J. (2010). Management and organizational behaviour (9 $9^{\text {th }}$ ed.) London: Prentice Hall.

12. National Center for Education Statistics (2003) NCES (2003). Digest of education statistics 2002 (NCES 2003 - 2006) Washington DC: US Government Printing Office.

13. Nato, P. B. (2016). Analysis of family structure influence on academic performance among secondary school students in Bungoma East Sub- 
County Kenya. International Journalof Secondary Education 4 (2) 122.

14. Onuka, A. O. U. \&Durowoju, E. O. (2011).Motivation and gender as determinants of achievement in senior secondary school economics.European Journal of Educational Studies 3(21), $209-216$.

15. Polednova, I.;Stranska, Z \&Niedobova, H. (2014).Achievement motivation of secondary school students in relation to their social position in the class.Problems of Psychology in the $21^{\text {st }}$ century, $8(1)$, $61-70$.

16. Reitman, D.; Rhode, P.;Hupp, S. D. A. \&Altebello, C. (2002). Development and validation of parental authoritative questionnaire revised. Journal of Psychopathology and Behavioural Assessment 24, $119-127$.

17. Seginer, R. (2006). Parents' educational involvement: A developmental ecology perspective. Parenting: Science Practice 6, 1 - 48 http://dx.doi.org/10.120/s/5327922par0601_1

18. Soltanzadeh, L.;Hashemi, S. R. N \&Shahi, S. (2013).The effect of active learning on academic motivation in high school students.Achieves of Applied Science Research 5(6), 127 - 131.

19. Star, M. L. (2011).The relationship between parenting styles, learning autonomy and scholastic achievement in undergraduate college students.Masters' thesis, Buncknell University.

20. UNICEF (2011). Family background and literacy performance http://www.oecd.org/dataoecd/33/9/336905591

21. Wakpainjan, P. \&Jadhau, S. (2012). The relationship between study habits, time management and achievement motivation of secondary school students.Aarhart Multidisciplinary Education Research Journal (AMIERJ) 1,( 111), 105 - 111.

22. Wigfield, A. \&Eccles, J. S. (2002).Development of achievement motivation. San Diego, C. A: Academic Press.

23. Winter, M. C. \&Yaffe, M. (2000).First-year students' adjustment to university life as a function of relationship with parents.Journal of Adolescence 15(1), 9 - 38 . 